\title{
Clinical comparison of $0.6 \%$ besifloxacin ophthalmic suspension and $1.5 \%$ azithromycin ophthalmic suspension in acute bacterial conjunctivitis
}

\author{
Meena $\mathbf{R}^{1}$, Gupta $\mathbf{M L}^{2}$ \\ ${ }^{1}$ Dr. Ravindra Kumar Meena, Assistant Professor, Jhalawar Medical college, Jhalawar, Rajasthan, India, ${ }^{2}$ Dr. M. L. \\ Gupta, Associate Professor, Department of Ophthalmology, Jhalawar Medical college, Jhalawar, Rajasthan, India.
}

Address for correspondence: Dr. Ravindra Kumar Meena, Email: drravindrameena@gmail.com

\begin{abstract}
Introduction: Acute bacterial conjunctivitis is one of the most common ocular infection seen in day to day clinical practice. Our purpose to conduct this study was to compare the outcome and efficacy of $0.6 \%$ besifloxacin ophthalmic suspension and $1.5 \%$ azithromycin ophthalmic suspension in acute bacterial conjunctivitis. Method: This is a Prospective, randomized, parallel-group, clinical study of acute bacterial conjunctivitis Conducted From July 2015 to Sept 2015 on 200 patients in the department of Ophthalmology at Jhalawar Medical College, Jhalawar.(raj.) All selected patients were divided into two groups of 100 each. Group A was treated by besifloxacin $0.6 \%$ ophthalmic suspension,where as group B was treated by $1.5 \%$ azithromycin ophthalmic suspension three times a day for 7 day. Observation was done on 3, 7 day regarding clinical resolution and side effect of these drugs in both groups. Result: Clinical resolution, complication, and side effects of these two drugs were analysed on day 3 and day 7 and found that $0.6 \%$ besifloxacin is significantly better than $1.5 \%$ azithromycin eye drop on day 3 and day 7 ( $p$ value $<0.5$ ) and also have less side effect ( $\mathrm{p}$ value $<0.5$ ). Conclusion: $0.6 \%$ besifloxacin is safe and efficacious in acute bacterial conjunctivitis in all age group.
\end{abstract}

Key words: Azithromycin, Besifloxacin, Conjunctivitis, Clinical Resolution.

\section{Introduction}

Acute Conjunctivitis is one of the most common eye infection in which the eyes become red and inflamed Bacterial infection accounts for up to $50 \%$ of all conjunctivitis cases in adults and as many as 70-80\% of cases in children. Bacterial conjunctivitis is characterised by mucopurulent discharge and conjunctival hyperaemia. Acute bacterial conjunctivitis is an infective condition that is not normally serious [1, 2].

In the developed world, the syndrome of acute 'red eye' accounts between $1 \%$ and $4 \%$ of consultations with primary care physicians and in the majority of cases an acute bacterial conjunctivitis is diagnosed [3].

Bacterial conjunctivitis can often be distinguished from viral conjunctivitis by signs such as mucopurulent discharge, chemosis, conjunctival congestion and

Manuscript received: $30^{\text {th }}$ Oct 2015

Reviewed: $8^{\text {th }}$ Nov 2015

Author Corrected: $20^{\text {th }}$ Nov 2015

Accepted for Publication: $2^{\text {nd }}$ Dec 2015 crusting with mucopurulence being a key distinguishing factor. The most common causative microbes in adults include gram-positive: Staphylococcus aureus, Staphylococcus epidermidis and Streptococcus pneumonia and the gram-negative pathogen Haemophilus influenza. S. aureus is the most common in adults, while children are most prone to infection by H. Influenza [4].

Mild cases are generally considered to be self-limiting, resolving in 5 to 10 days. However, current consensus supports the use of topical antibiotics as they (1) provide symptomatic relief, (2) hasten microbial remission (3) shorten disease duration, (4) reduce risk of developing sight-threatening complications, (5) reduce rate of re-infection, (6) prevent infection spread. Recent meta-analysis and a clinical trial showed that antibiotics provide significantly better rates of early clinical remission, and both early and late microbiological remission than placebo [5]. 
As treatment of bacterial conjunctivitis is often empirical and initiated before speciation of the ocular pathogen (that is, bacteriological culture), it is important to prescribe an antibiotic with a broad spectrum of antimicrobial activity. In this regard, topical fluoroquinolones have gained increasing use for the treatment of acute bacterial conjunctivitis. The fluoroquinolone family of antibiotics exhibits bactericidal activity by inhibiting two essential bacterial topoisomerase enzymes, DNA gyrase (topoisomerase II) and topoisomerase IV [6].

Once antibiotics are clinically indicated, the standard of care for bacterial conjunctivitis is broad-spectrum topical ophthalmic antibiotic eye drops. Various classes of antibiotics have been used including aminoglycosides, polymyxin B combinations, macrolides, sulfonamides and fluoroquinolones. Aminoglycosides (tobramycin and gentamycin) require frequent dosing (1-2 drops every four to six hours for ten days), which can lead to poor patient compliance. In addition, despite their frequent use, aminoglycosides demonstrate poor antimicrobial activity against Streptococci, which limits their use as a broad-spectrum treatment for conjunctivitis. Azithromycin is also less preferred due to its unequal gram-negative and positive coverage. Erythromycin is no longer recommended because its activity against $S$.aureus has diminished. Fluoroquinolones are still considered by many to be the antibiotics of choice for ocular infections on account of their broad-spectrum potency and low toxicity.

Besifloxacin ophthalmic suspension $0.6 \%$ is fourth generation topical fluoroquinolone recently approved for treatment of bacterial conjunctivitis in adults and children older than 1 year. Besifloxacin is the only fluoroquinolone specifically designed for ocular use. Unlike older antibiotics of this class, besifloxacin is not used for systemic infections. Restriction to topical use only, renders besifloxacin unique in its class and theoretically reduces the risk for the development of resistance due to decreased systemic exposure $[4,7,8]$.

Besifloxacin binds to DNA gyrase and topoisomerase IV, two enzymes that are critical for DNA replication in bacteria. Unlike previous generation in this class besifloxacin has a relative affinity for inhibiting the above enzymes [9]

\section{Material and Methods}

Design and Patients: This is a Prospective, randomized, parallel-group, clinical study of Acute bacterial conjunctivitis conducted From July 2015 to September 2015 on 200 patients in the department of ophthalmology at Jhalawar medical college, Jhalawar, Rajasthan

All selected patients were divided into two groups of 100 each.

\section{Group A}

$0.6 \%$ besifloxacin ophthalmic suspension group .

\section{Group B}

$1.5 \%$ azithromycin ophthalmic suspension group.

Inclusion Criteria: All patients of acute bacterial conjunctivitis as defined by mild to severe bulbar/fornices conjunctival congestion, discharge and stickiness in at least one eye for last 1 to 2 days.

Exclusion Criteria: Patients were excluded.

1. If they were associated with other ocular pathologies like chronic dacryocystitis, trichiasis, entropion

2. Patients having previous infection, and already on drug.

3. Patients having diabetes mellitus, using systemic corticosteroids.

4. Those had dry eye problem and who gave history of previous ocular surgery, laser treatment or trauma.

5. Systemic or ocular antibiotics, anti-inflammatory or immunosuppressive treatments were not authorised for use during the study.

The study was conducted in accordance with Good Clinical Practice. Written informed consent was obtained from all patients.

A detailed follow up was carried out at the Day1, Day3 and Day7 with regards to the :- Congestion, discharge, clinical resolution, complication

Study design and method: All the patients of acute bacterial conjunctivitis were allocated randomly in 1:1 ratio to one of the study group. We divided the work between two ophthalmologist, one of us had to performed the ophthalmologic examination, while a second was responsible for dispensing medications and assessing outcome,tolerance and safety.

Clinical feature assessments: The cardinal clinical signs of acute bacterial conjunctivitis (bulbar/fornices congestion and discharge) were assess for each eye by 
slit lamp and graded by a four point ordinal scale ( $0=$ absent; $1=$ mild; $2=$ moderate; $3=$ severe; $)$

Microbiological observation: A conjunctival swab was taken from each infected eye on day1 and day7. Bacterial specimens were analysed by giemsa staining in the department of ophthalmology, Jhalawar medical college.

Treatment pattern: After taken conjunctival swab all patients received antibiotic eyedrop either $1.5 \%$ azithromycin ophthalmic suspension or $0.6 \%$ besifloxacin ophthalmic suspension three times a day for 7 days.

All patients were advised to come on day 3 and day 7 for further follow up and look for congestion,discharge,clinical resolution and complication.

Safety and tolerance analysis: It was based on the observation of side effect related to study medication instillation like burning, stinging, itching, foreign body sensation and blurred vision.tolerance was assessed by asking the patients.

\section{Results}

In our study we enrolled 200 patients of acute bacterial conjunctivitis, out of which 100 patients were treated with $0.6 \%$ besifloxacin ophthalmic suspension(Group A) and 100 were with $1.5 \%$ azithromycin ophthalmic suspension(Group B).

Table No. 1: Distribution of cases according to age and gender

\begin{tabular}{|c|c|c|c|c|c|c|c|c|c|}
\hline \multirow{2}{*}{$\begin{array}{l}\text { Age in } \\
\text { group(yrs.) }\end{array}$} & \multicolumn{2}{|c|}{ Besifloxacin (100) } & \multirow{2}{*}{\multicolumn{3}{|c|}{ Total p value }} & \multicolumn{2}{|c|}{ Azithromycin group } & \multirow[t]{2}{*}{ Total } & \multirow[t]{2}{*}{$p$ value } \\
\hline & $\mathbf{M}$ & $\mathbf{F}$ & & & & $\mathbf{M}$ & $\mathbf{F}$ & & \\
\hline $1-15$ & 5 & 3 & 08 & $>0.05$ & NS & 08 & 02 & 10 & $>0.05 \quad \mathrm{NS}$ \\
\hline $16-30$ & 32 & 11 & 43 & $<0.05$ & SIG & 35 & 04 & 39 & $<0.05$ SIG \\
\hline $31-50$ & 34 & 07 & 41 & $<0.05$ & SIG & 28 & 13 & 41 & $<0.05 \quad$ SIG \\
\hline $51+$ & 06 & 02 & 08 & $>0.05$ & NS & 07 & 03 & 10 & $>0.05 \quad \mathrm{NS}$ \\
\hline Total & 77 & 23 & 100 & $<0.05$ & SIG & 78 & 22 & 100 & $<0.05$ SIG \\
\hline
\end{tabular}

Mean age of besifloxacin group $=30.16 \pm 12.33$ years

Mean age of azithromycin group $=30.93 \pm 13.16$ years

The difference between the mean ages of both group was not significant. In both groups p value was significant in 16-30, $31-50$, and $51+$

Table No. 2: Distribution of cases according to bulbar/fornices congestion

\begin{tabular}{|l|l|l|}
\hline & Besifloxacin(100) & Azithromycin(100) \\
\hline Absent & $05(5 \%)$ & $05(5 \%)$ \\
\hline Mild & $25(25 \%)$ & $22(22 \%)$ \\
\hline Moderate & $52(52 \%)$ & $58(58 \%)$ \\
\hline Severe & $18(18 \%)$ & $15(15 \%)$ \\
\hline Total & $\mathbf{1 0 0}$ & $\mathbf{1 0 0}$ \\
\hline
\end{tabular}

Group B patients had more fornices congestion.

Table No. 3: Distribution of cases according to purulent discharge

\begin{tabular}{|l|l|l|}
\hline & Besifloxacin(100) & Azithromycin(100) \\
\hline Absent & 00 & 00 \\
\hline Mild & $15(15 \%)$ & $12(12 \%)$ \\
\hline Moderate & $55(55 \%)$ & $58(58 \%)$ \\
\hline Severe & $30(30 \%)$ & $30(30 \%)$ \\
\hline Total & $\mathbf{1 0 0}$ & $\mathbf{1 0 0}$ \\
\hline
\end{tabular}

In this also Group B patients had more purulent discharge. 
Table No. 4: Distribution of cases according to clinical resolution

\begin{tabular}{|l|l|l|l|l|l|}
\hline Day & Besifloxacin(100) & Azithromycin(100) & P value & Z score & Significance \\
\hline 3 & $65(65 \%)$ & $48(48 \%)$ & .022 & 2.282 & Significant \\
\hline 7 & $95(95 \%)$ & $84(84 \%)$ & .021 & 2.307 & Significant \\
\hline
\end{tabular}

Most of the patients in Group A cured on day 3 and day 7.

Table No. 5: Distribution of cases according to complication.

\begin{tabular}{|l|l|l|l|l|l|}
\hline Complication & Besifloxacin(100) & Azithromycin(100) & P value & Z score & significance \\
\hline Keratitis & $05(5 \%)$ & $10(10 \%)$ & .283 & 1.074 & NS \\
\hline Corneal opacity & $03(3 \%)$ & $04(04 \%)$ & .182 & 1.334 & NS \\
\hline
\end{tabular}

Complications are not significant in both groups.

Table No. 6: Distribution of cases according to side effects of medication

\begin{tabular}{|l|l|l|l|l|l|}
\hline & Besifloxacin(100) & Azithromycin(100) & P value & Z score & Significance \\
\hline Burning & 35 & 50 & 0.045 & 2.003 & Sig. \\
\hline Itching & 40 & 45 & 0.567 & 0.572 & NS \\
\hline Stickness & 25 & 35 & 0.165 & 1.389 & NS \\
\hline Fb sensation & 40 & 55 & .047 & 1.982 & Sig. \\
\hline Blurred vision & 05 & 10 & .283 & 1.074 & NS \\
\hline
\end{tabular}

$\dagger$ NS-non significant

$\ddagger$ SIG-significant

Most of the patients had side effect of burning and foreign body sensation.

\section{Discussion}

In our study both groups had more male patients than female particularly in 16- 50 years age group because in our area males were more prone to do outdoor work which was supported by Eping et al, Abrahamian et al, Feingold et al, Buck et al [10-13]. Although the literature on the epidemiology of bacterial conjunctivitis contains several references to its highly contagious nature [10-13] no overall population-based data exists on the incidence of bacterial conjunctivitis. In the United States it is estimated that $23 \%$ of bacterial conjunctivitis cases occur in the 0-2 year age range, $28 \%$ occur in the 3-9 year range, $13 \%$ occur in the $10-$ 19 year range with the remaining $36 \%$ of cases occurring in adults. [14]

Mean age of besifloxacin group.was 30.16 \pm 12.33 , Mean age of azithromycin group was $30.93 \pm 13.16$ which was also not significant.

$73 \%$ Patients (Table no.2) showed moderate to severe bulbar congestion in azithromycin group, $70 \%$ patients shows moderate to severe bulbar congestion in besifloxacin group which did not had any significant value .

$85 \%$ patients in besifloxacin group and $88 \%$ patients in azithromycin group ( Table no. 3) showed moderate to severe purulent discharge. The severity of both these cardinal sign was not significantly different between these two group which was supported by Bremond gignac et al. [1]

In clinical resolution rate besifloxacin group had significantly high value in comparison to azithromycin group ( $\mathrm{p}$ value 0.022 )( $\mathrm{p}$ value 0.021 ) on day 3 and day 7 respectively which was supported by, Tepedino et al [15], Karpecki et al[16].

A 2009 multicenter, randomized Phase III study involving 390 patients demonstrated superior clinical resolution and bacterial eradication with besifloxacin. All patients had culture-confirmed bacterial conjunctivitis. Patients receiving besifloxacin demonstrated significantly more clinical resolution than patients receiving the vehicle at day $5(45.2 \%$ vs. 
$33.0 \%, \mathrm{p}=0.008)$ and day $8(84.4 \%$ vs. $69.1 \%, \mathrm{p}=$ $0.0011)$. In addition, besifloxacin-treated patients had significantly higher rates of microbial eradication at day $5(91.5 \%$ vs. $59.7 \%, \mathrm{p}=0.0001)$ and $8(88.4 \%$ vs. $71.7 \%, \mathrm{p}=, 0.0001)$ supported by, Tepedino et al, Karpecki et al[15,16].

Complication like keratitis and corneal opacity both remained non significant in both group(p value $>0.05$ ) (Table No.5).

Table No. 6 shows the side effects of both eye drops in which burning sensation and foreign body sensation was significantly higher in azithromycin group than besifloxacin group supported by Comstock T Let al[17] which showed that Systemic exposure of besifloxacin was negligible and the most common adverse events in patients receiving topical besifloxacin were local and included blurred vision $(2.1 \%)$, eye pain $(1.8 \%)$, eye irritation $(1.4 \%)$, nonspecific conjunctivitis $(1.2 \%)$ and eye pruritis $(1.1 \%)$. Besifloxacin topical administration did not affect visual acuity [18].

Results from this prospective, randomized, parallelgroup, clinical study of acute bacterial conjunctivitis which included 200 subjects provides evidence of the safety of besifloxacin given three times daily for 7 days in the treatment of bacterial conjunctivitis.

\section{Conclusion}

In summary, $0.6 \%$ besifloxacin ophthalmic suspension is an effective and safe therapeutic option for acute bacterial conjunctivitis in comparison to $1.5 \%$ azithromycin ophthalmic suspension. 0.6\% Besifloxacin provided a superior clinical cure rate on day 3 compared with $1.5 \%$ azithromycin ophthalmic suspension in all age group in acute bacterial conjunctivitis.

\section{Funding:Nil. Conflict of interest: Nil. Permission for IRB: Yes}

\section{Reference}

1. Bremond-Gignac D et al. Efficacy and safety of azithromycin $1.5 \%$ eye drops for purulent bacterial conjunctivitis in pediatric patients. Pediatr Infect Dis J 2014;0:1-7. doi:10.1136/bjophthalmol-2013-303888

2. Mark Abelson, Eugene Protzko, Aron Shapiro, Ana Garces-Soldana and Lyle Bowman.A randomized trial assessing the clinical efficacy and microbial eradication of $1 \%$ azithromycin ophthalmic solution vs tobramycin in adult and pediatric subjects with bacterial conjunctivitis. . Clin Ophthalmol. 2007 Jun; 1(2): 177182 .

3. Sheikh A, Hurwitz B. Topical antibiotics for acute bacterial conjunctivitis: a systematic review. Br J Gen Pract. 2001 Jun;51(467):473-7.

4. S. Khimdas, K.L. Visscher, and C.M.L. Hutnik Besifloxacin Ophthalmic Suspension: Emerging Evidence of its Therapeutic Value in Bacterial Conjunctivitis Ophthalmol Eye Dis. 2011; 3: 7-12. doi: 10.4137/OED.S4102

5. Isabelle Cochereau, Amel Meddeb-Ouertani, Moncef Khairallah, Abdelouahed Amraoui, Khalid Zaghloul, Mihai Pop,Laurent Delval, Pascale Pouliquen, Radhika Tandon, Prashant Garg, Pablo Goldschmidt, and Tristan Bourcier.3-day treatment with azithromycin $1.5 \%$ eye drops versus 7-day treatment with tobramycin $0.3 \%$ for purulent bacterial conjunctivitis: multicentre, randomised and controlled trial in adults and children .Br J Ophthalmol. 2007 Apr; 91(4): 465-469.

6. D G Hwang, D J Schanzlin, M H Rotberg, G Foulks, M B Raizman, and the Levofloxacin Bacterial Conjunctivitis Placebo-controlled Study Group* A phase III, placebo controlled clinical trial of $0.5 \%$ levofloxacin ophthalmic solution for the treatment of bacterial conjunctivitis Br J Ophthalmol2003;87:10041009)

7. Comstock TL, Karpecki PM, Morris TW, Zhang JZ. Besifloxacin: a novel anti-infective for the treatment of bacterial conjunctivitis. Clin Ophthalmol. 2010 Apr 26;4:215-2.

8. Ranjan Malhotra, Stacey Ackerman, Lynne S. Gearinger , Timothy W. Morris, The Safety of Besifloxacin Ophthalmic Suspension $0.6 \%$ Used Three Times Daily for 7 Days in the Treatment of Bacterial Conjunctivitis. Catherine Allaire Drugs R D (2013) 13:243-252. DOI 10.1007/s40268-0130029-1

9. Cambau E, Matrat S, Pan XS, Roth Dit Bettoni R, Corbel C, Aubry A, Lascols C, Driot JY, Fisher LM. Target specificity of 
the new fluoroquinolone besifloxacin in Streptococc us pneumoniae, Staphylococcus aureusand Escherichia coli. J Antimicrob Chemother. 2009 Mar;63(3):443-50. doi: 10.1093/jac/dkn528. Epub 2009 Jan 15.

10. Chaberny IE, Schnitzler P, Geiss HK, Wendt C. An outbreak of epidemic keratoconjunctivtis in a pediatric unit due to adenovirus type 8 . Infect Control Hosp Epidemiol. 2003 Jul;24(7):514-9.

11. Abrahamian FM. Update on emerging infections: news from the Centers for Disease Control and Prevention. MMWR Morb Mortal Wkly Rep. 2002;51:205-207.

12. Feingold EK. The outbreak of conjunctivitis at Dartmouth. N Engl J Med. 2003 Jun 19;348(25):2577-8; author reply 2577-8.

13. Buck JM, Lexau C, Shapiro M, Glennen A, Boxrud DJ, Koziol B, Whitney CG, Beall B, Danila R, Lynfield R. A community outbreak of conjunctivitis caused by nontypeable Streptococcus pneumoniae in Minnesota. Pediatr Infect Dis J. 2006;25:906-911.

14. Lichtenstein SJ, Rinehart M; Levofloxacin Bacterial Conjunctivitis Study Group. Efficacy and safety of $0.5 \%$ levofloxacin ophthalmic solution for the treatment of bacterial conjunctivitis in pediatric patients. J AAPOS. 2003 Oct;7(5):317-24.

15. Tepedino ME, Heller WH, Usner DW, et al. Phase III efficacy and safety study of besifloxacin ophthalmic suspension $0.6 \%$ in the treatment of bacterial conjunctivitis. Curr Med Res Opin. 2009;25(5):115969. doi: 10.1185/03007990902837919.

16. Karpecki P, Depaolis $M$, Hunter JA, et al. Besifloxacin ophthalmic suspension $0.6 \%$ in patients with bacterial conjunctivitis: a multicenter, prospective, randomized, double-masked, vehicle-controlled, 5-day efficacy and safety study. Clin Ther. 2009;31(3):51426. Doi: 10.1016/j.clinthera.2009.03.010

17. Comstock TL, Paterno MR, Usner DW, Pichichero ME. Efficacy and safety of besifloxacin ophthalmic suspension $0.6 \%$ in children and adoles- cents with bacterial conjunctivitis: a post hoc, subgroup analysis of three randomized, double-masked, parallel-group, multicenter clinical trials. paediatr Drugs. 2010;12(2):105-12. Doi: 10.2165/11534380000000000-00000

18. Comstock TL, Paterno MR, Decory HH, Usner DW. Safety and tolerability of besifloxacin ophthalmic suspension $0.6 \%$ in the treatment of bacterial conjunctivitis: data from six clinical and phase I safety studies. Clin Drug Investig. 2010;30(10):675-85. Doi: 10.2165/11536720-000000000-00000.

\section{How to cite this article?}

Meena R, Gupta ML. Clinical comparison of $0.6 \%$ besifloxacin ophthalmic suspension and $1.5 \%$ azithromycin ophthalmic suspension in acute bacterial conjunctivitis. Int J Med Res Rev 2015;3(11):1288-1293. doi: 10.17511/ijmrr.2015.i11.234. 